\title{
Temperature Dependent Ultrasonic Study in Scandium Antimonide Semiconductor
}

\author{
A. K. GUPTA ${ }^{1}$, S. SRIVASTAVA ${ }^{2}$, and K. B. THAPA ${ }^{3}$ \\ ${ }^{1}$ Academic Department, National Institute of Open Schooling (NIOS), \\ Ministry of HRD, Govt. of India, NOIDA-201309, India \\ ${ }^{2}$ Materials Science \& Metallurgical Engineering \\ Maulana Azad National Institute of Technology, Bhopal-462051 \\ ${ }^{3}$ Department of Physics, \\ University Institute of Engineering \& Technology \\ Chhatrapati Shahu ji Maharaj University, Kanpur-208024 (UP) INDIA \\ s.srivastava.msme@gmail.com
}

Received 30 June 2011; Accepted 27 August 2011

\begin{abstract}
In this paper analysis of wave propagation of elastic wave in scandium antimonide semiconductor was investigated. In scandium antimonide semiconductor, $\mathrm{NaCl}$ structure was found. Ultrasonic properties like ultrasonic attenuation, sound velocities, acoustic coupling constants, and thermal relaxation time have been investigated in cubic scandium antimonide semiconductor. Second and third order elastic constant have been computed for the evaluation of above said ultrasonic properties. Second and third elastic constant was studied at the various temperatures. Longitudinal and shear velocity was calculated by using the elastic constant. Longitudinal and shear velocity increase with increase the temperature. Ultrasonic attenuation either from longitudinal or shear wave propagation in cubic materials increase with increase the temperature.
\end{abstract}

Keywords: Scandium antimonide, Ultrasonic attenuation, Second and third elastic constant.

\section{Introduction}

Ultrasonic's have become a powerful tool to characterize the material systems of different types like the interface between hard and soft solids and liquids ${ }^{1-2}$. Study of propagation behavior of ultrasonic is related to the microstructural phenomena in the materials and other thermo-physical properties of the materials ${ }^{3-4}$. Group III-V wide-gap semiconductor materials are very important because of their Opto-electronic technological applications as a commercial short wavelength light-emitting diode, laser diode, transparent conductors, solar cells, high-density optical memory and visual display [5].This importance arises from the 
role of the d-electrons in the valance band in hybridization, which tends to open a gap at the band crossing and make angular momentum labeling no longer suitable.

Within my best knowledge, less is known about $\mathrm{ScSb}$ and $\mathrm{ScP}$ compounds. Tabboune et al investigated the structural and electronic properties of $\mathrm{ScSb}$ and ScP III$\mathrm{V}$ materials within a version of the first principles full potential linear muffin-tin orbital's method (FP-LMTO) ${ }^{6}$. They found that a transition from rock salt (RS) to cesium chloride $(\mathrm{CsCl})$ structure is possible at high pressure $(87.75 \mathrm{GPa}$ for $\mathrm{ScSb}$ and $330 \mathrm{GPa}$ for $\mathrm{ScP})$.

Scandium antimonide with NaCl-type structure has attracted much interest since the discovery of their anomalous physical properties ${ }^{7}$. The high pressure structural behavior of semiconductor scandium antimonide is very interested ${ }^{8}$. The temperature dependence behavior of this binary $\mathrm{AB}$ compound with a NaCl-type $\left(\mathrm{B}_{1}\right)$ structure has been popular topic on condensed matter research. This material is technologically important having many applications ranging from catalysis to microelectronics. Therefore we have chosen the materials for present investigation.

Aim of the study is to establish the theoretical approach for the determination of higher order elastic constants of the materials at high temperatures. Finally the theory will be established for the determination of ultrasonic attenuation and related parameters in these materials at high temperatures along different crystallographic directions. Also the characteristic behavior of ultrasonic propagation in the materials has been also discussed.

\section{Experimental}

Theory is categorized in two parts.

Second and Third order elastic constants (SOEC and TOEC):

The potential used for evaluation of SOEC and TOEC of the form:

$$
\phi(\mathrm{R})=\phi(\mathrm{C})+\phi(\mathrm{r})
$$

Where $\phi(C)$ is electrostatic potential and $\phi(r)$ is the repulsive potential given as:

$$
\phi(C)= \pm \frac{e^{2}}{r} \text { and } \phi(r)=A \exp (-r / b)
$$

Where e is the electronic charge, $\mathrm{r}$ is the nearest neighbor distance and $\mathrm{A}$ is the strength parameter. Following Brugger's definition ${ }^{9}$ of elastic constants at $0 \mathrm{~K}$ and starting from nearest neighbor distance and hardness parameter of the substance and taking interaction effective up to second neighbor distance, according to lattice dynamics developed by Leibfried and Ludwig and Ghate ${ }^{10,11}$, lattice energy changes with temperature. Hence adding vibrational energy contribution to static elastic constants, one gets $\mathrm{C}_{\mathrm{IJ}}$ and $\mathrm{C}_{\mathrm{IJK}}$ at required temperature.

$$
\begin{gathered}
\mathrm{C}_{\mathrm{IJ}}=\mathrm{C}_{\mathrm{IJ}}^{0}+\mathrm{C}_{\mathrm{IJ}}^{\mathrm{Vib}} \\
\mathrm{C}_{\mathrm{IJK}}=\mathrm{C}_{\mathrm{IJK}}^{0}+\mathrm{C}_{\mathrm{IJK}}^{\mathrm{Vib}}
\end{gathered}
$$

Where superscript 0 has been used to denote SOEC and TOEC at $0 \mathrm{~K}$ (static elastic constants) and superscript vib. has been used to denote SOEC and TOEC at particular temperature. 


\section{Ultrasonic attenuation}

In the second part of present investigation, Mason's theory ${ }^{12-13}$ is still widely used successfully to study the ultrasonic attenuation at room temperature in solids. It is more reliable theory to study anhormonicity of the crystal as it involves elastic constants directly through non-linearity parameter (D) in the determination of ultrasonic attenuation $\left(\alpha / f^{2}\right)$. According to the theory, ultrasonic attenuation due to phonon-phonon interactions at high temperatures can be given as:

$$
\left(\alpha / f^{2}\right)_{A k h .}=\frac{E_{0}(D / 3) 4 \pi^{2} \tau}{2 \rho V^{3}}
$$

Where non-linearity parameter (acoustic coupling constant) is:

$$
D=9<\left(\gamma_{i}^{j}\right)^{2}>-\left(3<\gamma_{i}^{j}>^{2} C_{V} T\right) / E_{0}
$$

Thermal relaxation time

$$
\tau_{\text {th }}=\tau_{\text {sh }}=\frac{\tau_{\text {long }}}{2}=\frac{3 K}{C_{V} \bar{V}^{2}}
$$

Debye average velocity of ultrasonic waves as:

$$
\bar{V}=\left(\frac{1}{3} \frac{1}{V_{l}^{3}}+\frac{2}{3} \frac{1}{V_{s}^{3}}\right)^{-1 / 3}
$$

Thermo elastic loss is given by:

$$
\left(\alpha / f^{2}\right)_{t h}=\frac{4 \pi^{2}<\gamma_{i}^{j}>^{2} K T}{2 \rho V_{l}^{5}}
$$

\section{Evaluations of the results}

The nearest neighbor distance $\left(\mathrm{r}_{0}\right)$ is taken $2.992 \AA$ and hardness parameter $(\mathrm{b})$ is taken $0.310 \AA$ for $\mathrm{ScSb}^{6,14-15}$. The present values of SOEC and TOEC are given in Table 1 . The value of specific heat per unit volume $\left(\mathrm{C}_{\mathrm{V}}\right)$ and thermal energy density $\left(\mathrm{E}_{0}\right)$ are determined by $\theta_{D} / T$ tables in AIP Handbook ${ }^{16}$. The values of thermal relaxation time $\left(\tau_{\text {th }}\right)$, thermal conductivity $(\mathrm{K})$, specific heat per unit volume $\left(\mathrm{C}_{\mathrm{V}}\right)$ and Debye average velocity $(\overline{\mathrm{V}})$ are presented in Table 2 . The non-linearity parameter is a function of Grüneisen parameter $\left\langle\gamma_{i}^{j}\right\rangle$, specific heat per unit volume $\left(\mathrm{C}_{\mathrm{V}}\right)$, thermal energy density $\left(\mathrm{E}_{0}\right)$ and temperature $(\mathrm{T})$. Grüneisen parameters are determined using elastic constants (SOEC and TOEC) ${ }^{12-13}$. The values of non-linearity parameters (acoustic coupling constants) are presented in Table 3. Finally ultrasonic attenuation coefficients $\left(\alpha / f^{2}\right)_{A k h}$. due to phonon-phonon interaction and due to thermo-elastic loss $\left(\alpha / f^{2}\right)_{t h}$ are calculated using eqns. (5) and (9) respectively, are shown in Figure 3.1-3.3. In order to verify the validity of the present investigation the simple way to compare the calculated second and third order elastic constants, thermal relaxation time, acoustic coupling constants, ultrasonic attenuation coefficients due to phonon-phonon interaction and thermoelastic loss with the values for similar solids.

\section{Second and third order elastic constants (SOEC and TOEC)}

It is clear from the Table 1 that out of nine elastic constants, four i.e. $\mathrm{C}_{12}, \mathrm{C}_{111}, \mathrm{C}_{123}$, and $\mathrm{C}_{166}$ are decreasing with temperature while others $\mathrm{C}_{11}, \mathrm{C}_{44}, \mathrm{C}_{112}$, and $\mathrm{C}_{144}$ increase with temperature, while value of $\mathrm{C}_{456}$ remains unchanged. This type of behavior has been found in other NaCl-type materials $s^{17-19}$. It is also found that values of $\mathrm{C}_{111}, \mathrm{C}_{112}$, and $\mathrm{C}_{166}$ are negative, which is the same nature as in like materials ${ }^{17-22}$. 


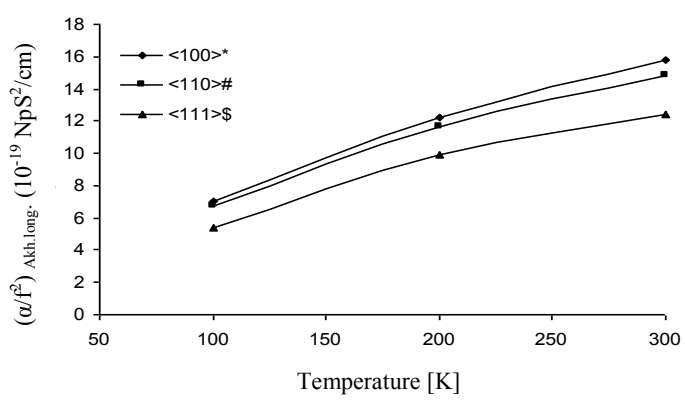

Figure 3.1. $\left(\alpha / \mathrm{f}^{2}\right)$ Akh.long. $V s$. temperature $[\mathrm{K}]$ for $\mathrm{ScSb}$.

*longitudinal wave along $<100>$ direction, \# longitudinal wave along $<110>$ direction, \$ longitudinal wave along $\langle 111\rangle$ direction.

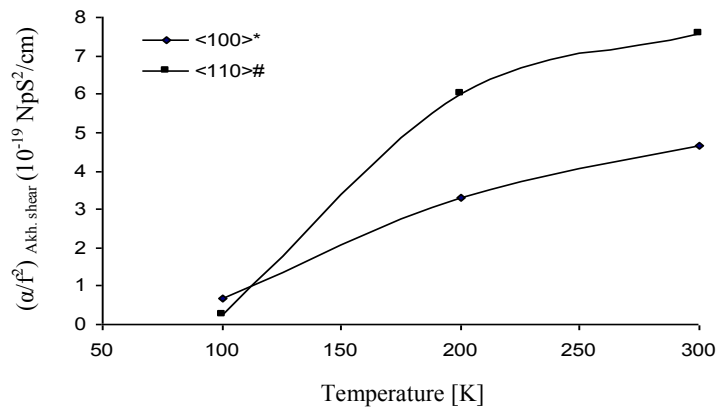

Figure 3.2. $\left(\alpha / \mathrm{f}^{2}\right)$ Akh. shear $V s$. temperature $[\mathrm{K}]$ of $\mathrm{ScSb}$.

$*$ shear wave along $<100>$ direction \# shear wave along $<110>$ direction and polarized along $<001>$ direction.

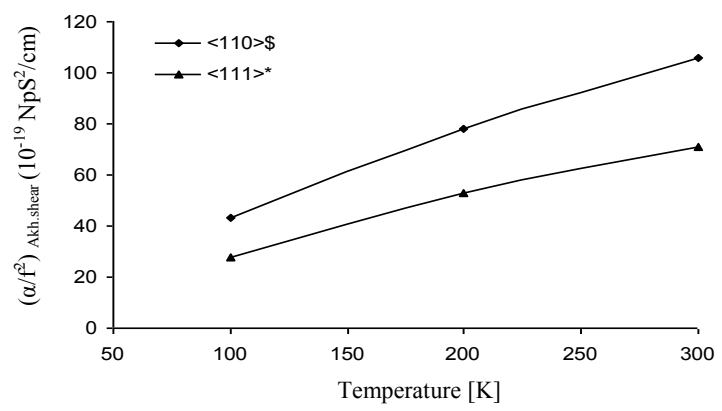

Figure 3.3. $\left(\alpha / \mathrm{f}^{2}\right)$ Akh.shear $V s$. temperature $[\mathrm{K}]$ for $\mathrm{ScSb}$.

$\$$ shear wave along $<110>$ direction and polarized along $<110>$ direction, * shear wave along $<111>$ direction and polarized along $<\overline{1} 10>$ direction.

Table 1. Second and third order elastic constants (SOEC and TOEC) in the unit of $10^{11}$ dyne $/ \mathrm{cm}^{2}$ of scandium antimonide in the temperature range $100-300 \mathrm{~K}$.

\begin{tabular}{cccccccccc}
\hline Temp.[K] & $\mathrm{C}_{11}$ & $\mathrm{C}_{12}$ & $\mathrm{C}_{44}$ & $\mathrm{C}_{111}$ & $\mathrm{C}_{112}$ & $\mathrm{C}_{123}$ & $\mathrm{C}_{144}$ & $\mathrm{C}_{166}$ & $\mathrm{C}_{456}$ \\
\hline 100 & 4.896 & 1.174 & 1.258 & -80.764 & -4.764 & 1.638 & 2.140 & -5.103 & 2.123 \\
200 & 5.057 & 1.096 & 1.236 & -81.501 & -4.454 & 1.153 & 2.156 & -5.123 & 2.123 \\
300 & 5.233 & 1.017 & 1.268 & -84.393 & -4.142 & 0.668 & 2.172 & -5.140 & 2.123 \\
\hline
\end{tabular}




\section{Thermal relaxation time}

It can be seen from Tables 2 that order of thermal relaxation time $\left(\tau_{\text {th }}\right)$ is $10^{-14} \mathrm{sec}$. for $\mathrm{ScSb}$ semiconductor due to their different thermal conductivity values of the order of $10^{2}$ $\mathrm{erg} / \mathrm{sec} . \mathrm{cm} \cdot \mathrm{K}^{23-25}$.

Table 2. Longitudinal and shear velocities $\left(\mathrm{V}_{1}\right.$ and $\left.\mathrm{V}_{\mathrm{s}}\right)$ in the unit of $10^{5} \mathrm{~cm} / \mathrm{sec}$, Debye average velocity $(\bar{V})$ in the unit of $10^{5} \mathrm{~cm} / \mathrm{sec}$, thermal relaxation time $\left(\tau_{\text {th }}\right)$ in the unit of $10^{-14}$ sec, specific heat $\left(\mathrm{C}_{\mathrm{v}}\right)$ in the unit of $10^{6} \mathrm{erg} / \mathrm{cm}^{3} \mathrm{~K}$, internal energy $\left(\mathrm{E}_{0}\right)$ in the unit of $10^{8}$ $\mathrm{erg} / \mathrm{cm}^{3}$ and thermal conductivity $(\mathrm{K})$ in the unit of $10^{2} \mathrm{erg} / \mathrm{sec} . \mathrm{cm} . \mathrm{K}$ of scandium antimonide in the temperature range $100-300 \mathrm{~K}$.

\begin{tabular}{cccccccc}
\hline Temp.[K] & $\mathrm{V}_{1}$ & $\mathrm{~V}_{\mathrm{s}}$ & $\overline{\mathrm{V}}$ & $\tau_{\text {th }}$ & $\mathrm{C}_{\mathrm{v}}$ & $\mathrm{E}_{0}$ & $\mathrm{~K}$ \\
\hline 100 & 2.935 & 1.488 & 1.648 & 1.074 & 7.417 & 4.228 & 7.212 \\
200 & 3.008 & 1.503 & 1.666 & 0.730 & 8.054 & 11.935 & 5.442 \\
300 & 3.083 & 1.517 & 1.683 & 0.639 & 8.112 & 19.655 & 4.902 \\
\hline
\end{tabular}

\section{Acoustic coupling constants (D)}

The variation of $\mathrm{D}$ with temperature is presented in Table 3. It can be seen that acoustic coupling constant decreases with the temperature and this behavior can be related with atomic number and atomic mass, as atomic number and atomic mass decreases with the value of acoustic coupling constant in these materials. The acoustic coupling constant ratio $\mathrm{D}_{1} / \mathrm{D}_{\mathrm{s}}$ along $<100>$ lies between $14-15, \mathrm{D}_{1} / \mathrm{D}_{\mathrm{s} 1}$ along $<110>$ and shear wave polarized along $<001>$ is about $7-10$ and $D_{\mathrm{s} 2} / \mathrm{D}_{1}$ along $<110>$, shear wave polarized along $<110>$ and $\mathrm{D}_{\mathrm{s}} / \mathrm{D}_{1}$ along $<111>$ shear wave polarized along $<110>$ are about $1-1.8$ which is comparable with that in experimental values of $\mathrm{NaCl}$-type $\mathrm{LiF}^{26}$ and other like crystals ${ }^{27}$.

Table 3. Acoustic coupling constants $\left(D_{1}\right.$ for longitudinal wave, $D_{S}$ for shear wave along $<100>$ orientation and ratio of $\left.\mathrm{D}_{1} \& \mathrm{D}_{\mathrm{S}}\right),\left(\mathrm{D}_{\mathrm{S} 1}{ }^{*}\right.$ for shear wave polarized along $<001>$ orientation, $\mathrm{D}_{\mathrm{S} 2}{ }^{\#}$ for shear wave polarized along $<110>$ orientation, and ratio of $D_{1} \& D_{\mathrm{S} 1}, D_{\mathrm{S} 2} \& D_{1}$ ) along $<110>$ orientation, $\left(\mathrm{D}_{\mathrm{S}}{ }^{\$}\right.$ for shear wave polarized along $<110>$ orientation and ratio of $\left.\mathrm{D}_{1} \& \mathrm{D}_{\mathrm{S}}{ }^{\$}\right)$ along $<111>$ orientation of scandium antimonide in the temperature range $100-300 \mathrm{~K}$.

\begin{tabular}{ccccc}
\hline Temp. $[\mathrm{K}] \rightarrow$ & Parameters & 100 & 200 & 300 \\
\hline \multirow{3}{*}{$<100>$} & $\mathrm{D}_{1}$ & 18.494 & 17.743 & 16.847 \\
& $\mathrm{D}_{\mathrm{S}}$ & 1.253 & 1.205 & 1.192 \\
& $\mathrm{D}_{1} / \mathrm{D}_{\mathrm{S}}$ & 14.760 & 14.725 & 14.133 \\
& $\mathrm{D}_{1}$ & 17.658 & 16.922 & 15.610 \\
$<110>$ & $\mathrm{D}_{\mathrm{S}}{ }^{*}$ & 1.834 & 2.183 & 1.930 \\
& $\mathrm{D}_{\mathrm{S} 2}{ }^{*}$ & 29.568 & 28.275 & 27.067 \\
& $\mathrm{D}_{1} / \mathrm{D}_{\mathrm{S} 1} *$ & 9.628 & 7.752 & 8.088 \\
& $\mathrm{D}_{\mathrm{S} 2} / \mathrm{D}_{1}$ & 1.675 & 1.671 & 1.734 \\
& $\mathrm{D}_{1}$ & 14.400 & 14.378 & 13.300 \\
& $\mathrm{D}_{\mathrm{S}}{ }^{\$}$ & 19.752 & 19.119 & 18.328 \\
& $\mathrm{D}_{\mathrm{S}}{ }^{\$} / \mathrm{D}_{1}$ & 1.372 & 1.330 & 1.378 \\
\hline
\end{tabular}


attenuation due to phonon-phonon interaction and due to thermoelastic mechanism

In the present investigation it is pointed out that attenuation varies with temperature as $\alpha=\alpha_{0} T^{n}$ where $\alpha_{0}$ and $n$ are constants. It is obvious from Figure 3.1-3.3 that the ultrasonic attenuation due to p-p interaction $\left(\alpha / \mathrm{f}^{2}\right)_{\text {Akh.long. }}$ for longitudinal wave and $\left(\alpha / \mathrm{f}^{2}\right)_{\text {Akh.shear }}$ for shear wave increases with temperature in scandium antimonide. The values of $\left(\alpha / \mathrm{f}^{2}\right)_{\text {Akh.long. }}$ are greater than that of $\left(\alpha / \mathrm{f}^{2}\right)_{\text {Akh.shear }}$ along $<100>$ direction and along $<110>$ direction (shear wave polarized along $<001>$

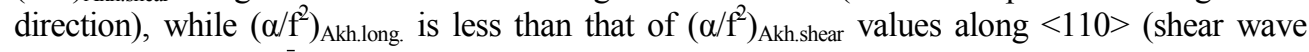
polarized along $<110>$ direction) and $<111>$ direction (shear wave polarized along $<110>$ direction), which has been observed experimentally in semiconductors ${ }^{27-29}$.

It is clear from the Figures 3.1-3.3 that the values of ultrasonic attenuation due to p-p interaction are found highest in $\mathrm{ScSb}$ due to their thermal conductivity values. Order of the attenuation in $\mathrm{ScSb}$ semiconductor is anomalous due to their thermal conductivity values. The ultrasonic attenuation of $\mathrm{ScSb}$ can be compared with the semiconductors ${ }^{27-29}$. There is good agreement between the attenuation of present material and other same type materials. Ultrasonic attenuation due to thermo elastic loss $\left(\alpha / \mathrm{f}^{2}\right)_{\text {th }}$ is negligible in comparison to attenuation due to p-p interaction.

\section{Conclusion}

On the basis of above analysis the following conclusions can be drawn.

1. The method of calculation of SOEC/TOEC at different temperatures is justified and can be utilized for the determination of ultrasonic properties of these materials.

2. Second and third order elastic constant changes with change the temperature. These elastic are also changed with according to the crystallographic direction of the materials.

3. Theoretical approach utilized for the calculation of temperature dependency of ultrasonic attenuation in the materials is well established.

4. Thermal conductivity of the material is the prominent contributor for the difference of ultrasonic attenuation Scandium antimonide semiconductor.

5. The results may be utilized for the materials processing in the industries.

\section{References}

1. Glorieux C, de Rostyne K V, Nelson K, Gao W, Lauriks W and Thoen J, J Acoust Soc Am., 2001, 110(3), 1299.

2. Ogi H, Tsujimoto A, Nishimura S and Hirao M, Acta Mater., 2005, 53(2), 513.

3. Rajendran V, Kumaran S M, Sivasubramanium V, Jayakumar T, and Raj Baldev, $J$ Non-Cryst Solids., 2001, 296, 39.

4. Kaack M, Holtfort I D, Yohannes T and Pelzl J, Mat Sci Engg A, 2004, 378, 119.

5. Amrani B, Maachou A. and Driz M, Physica B: Condensed Matter., 2007, 17, 384-389.

6. Tabboune A, Rached D, Benzair A, Sekkal N and Belbachir A, Physica Status Solidi (B), 2006, 243, 2788-2795.

7. Bucher E, Andres K, di Salvo F J, Maita J P, Gossard A C, Cooper A S and Hull Jr G W, Phys Rev B, 1975, 11, 500.

8. Hayashi J, Shirotani I, Hirano K, Ishimatsu N, Shimomura O and Kikegawa T, Solid State Commun., 2003, 125, 543.

9. Brugger K, Phys Rev A, 1964, 133, 1611.

10. Leibfried G and Ludwig W, Theory of anhormonic effect in crystals: F. Seitz and D. Turnbull (Ed.), in Solid State Physics, Academic Press, New York, 1961, 12, 276-444.

11. Ghate P B, Phys Rev A, 1965, 139, 1666. 
12. Mason W P, Effect of impurities and phonon processes on ultrasonic attenuation in Ge, crystal quartz and Si, in Physical Acoustics, Part B, vol. 3, Academic Press, New York, 3, 237-286.

13. Mason W P and Bateman T B, J Acoust Soc Am., 1966, 40, 852.

14. Wyckoff R W G, Crystal structure, Interscience Publications, New York, $2^{\text {nd }}$ Edition, 1963.

15. Tosi M P, Cohesion of ionic solids in the Born Model, Seitz F and Turnbull D, (Ed.), in Solid State Physics, Academic Press, New York, 1964, 16.

16. Gray D E, (Ed.), American Institute of Physics Handbook, McGraw Hill, New York III ${ }^{\text {rd }}$ edition.

17. Yadav R R and Singh D, Acoust Phys., 2003, 49, 595.

18. Yadav R R and Singh D, J Phys Soc Jap., 2001, 70, 1825.

19. Yadav R R and Shanker K, Ultrasonics Internationals'93 conference proceeding (pp. 459).

20. Mori S. and Hiki Y, J Phys Soc Jap, 1975, 45, 1449.

21. Kor S K, Mishra P K and Tandon U S, Solid State Commun., 1974, 15, 449

22. Kor S K and Khare R P, Acta Physica Polonica A, 1980, 58, 725.

23. Singh D and Awasthi P, J Acoust Soc Ind., 2003, 31, 343.

24. Singh D, Yadav R R and Tiwari A K, Ind J Pure Appl Phys., 2002, 40, 845.

25. Rajagopalan S, and Joharapurkar D N, J Appl Phys., 1983, 54, 3166.

26. Hanson R C, J Phys Chem Solids, 1967, 28, 475.

27. Shukla S S. and Yun S S, J Acoust Soc Am., 1986, 70, 1723.

28. Sakurai H, Yamanaka F, Yoshida K, Ohshima N and Suzuki K, J Appl Phys., 1984, 56, 1613.

29. Hrivnak L and Kovar J, Physica Status Solidi, 1967, 23, 189. 


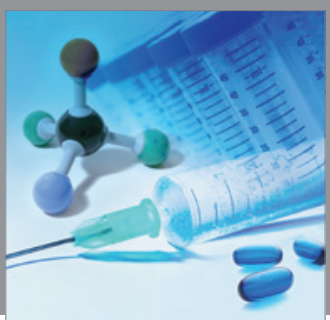

International Journal of

Medicinal Chemistry

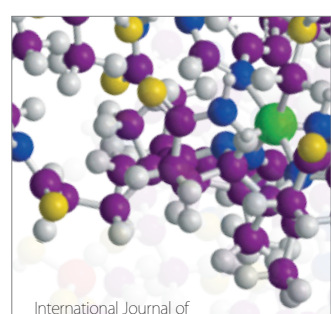

Carbohydrate Chemistry

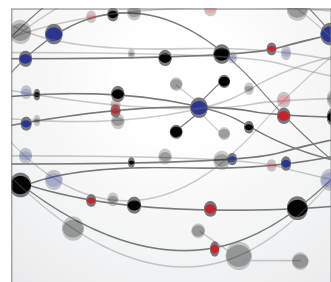

The Scientific World Journal
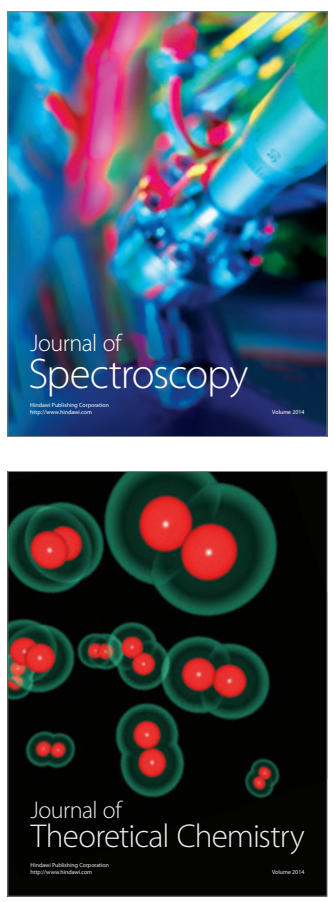
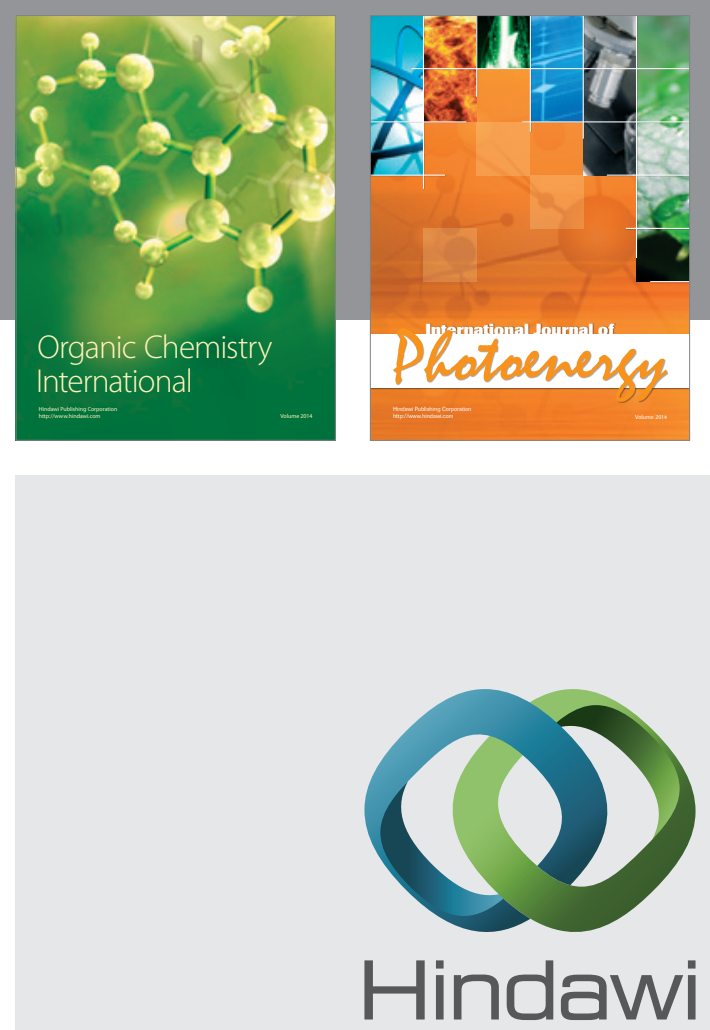

Submit your manuscripts at

http://www.hindawi.com
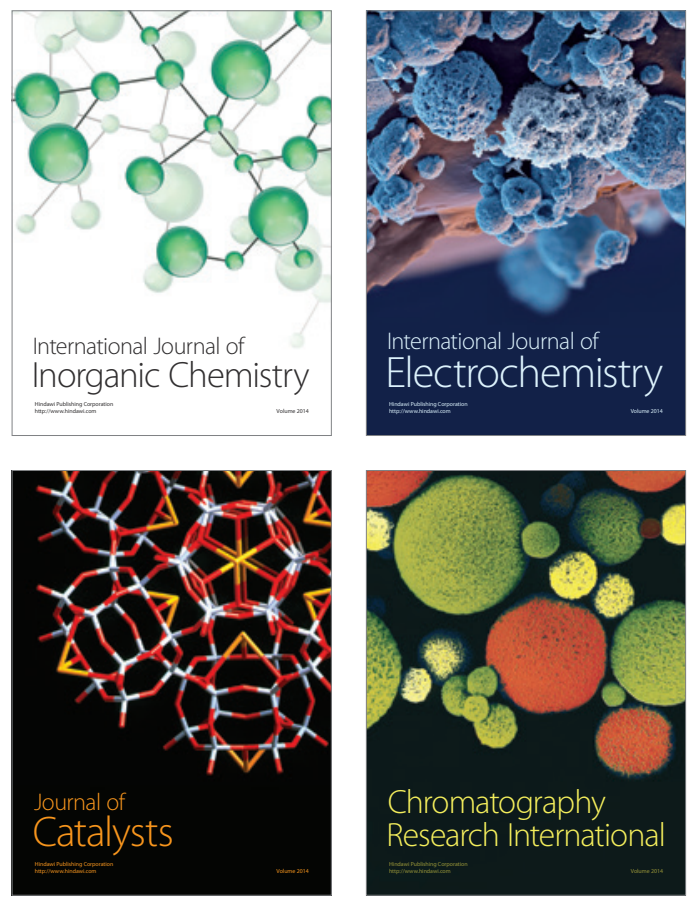
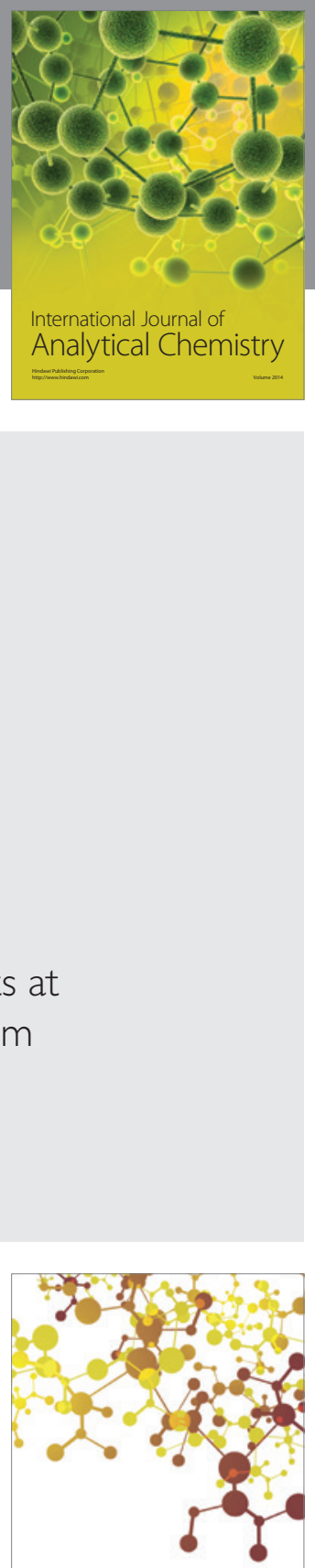

Journal of

Applied Chemistry
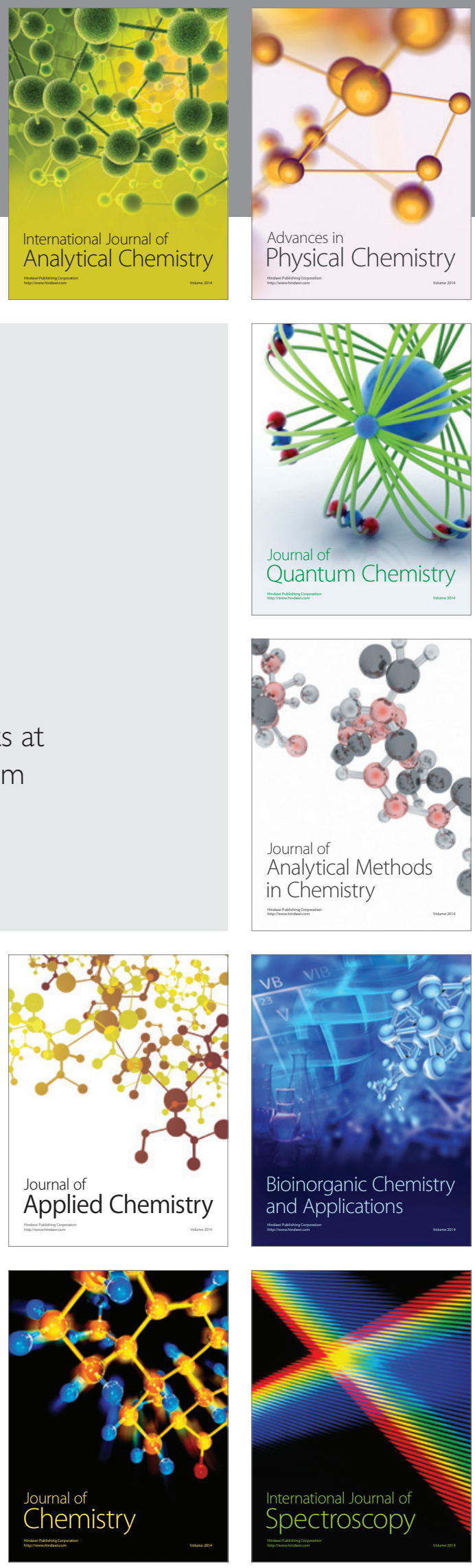